\title{
Steady state CFD analysis of heat transfer coefficient in pressurised pipes of super-heater of OP210 steam boiler
}

\author{
Mariusz Granda* \\ Institute of Thermal Power Engineering, Cracow University of Technology, Poland
}

\begin{abstract}
The aim of the paper is Computational Fluid Dynamics (CFD) analysis of Wall Heat Transfer Coefficient (WHTC) of pressurized pipe as a part of super-heater of the OP210 boiler. The object of the investigation is convection from saturated steam to the wall of the pipe, which works under high pressure and high temperature. The analysis is an approach to obtain exact solutions of WHTC according to the third type boundary condition compared to direct results from CFD analysis. The paper consists of three-step approach typical for CFD analysis: (i) Pre-Processing, the most elaborated part of the analysis where knowledge about super-heaters, turbulence, velocity profile is important to 3D model, mesh and boundary condition definition. (ii) Simulation of steady state turbulent flow until convergence criteria are met. (iii) Post-Processing where different approaches to the WHTC are shown in comparison. Also, the investigation includes two different types of meshes (where a different number of inflation layers are used) and comparison between kepsilon and Solid Shear Stress (SST) turbulence model.
\end{abstract}

\section{Introduction}

Super-heaters are significant accessories of steam boilers in terms of Rankine's cycle efficiency [1,2]. To improve it, as high as possible parameters of steam should be used. Also, dehumidification of the vapour is very important due to the erosion of turbine blades [2]. In all of these cases, super-heaters are used. They are built from coils of seamless, bare tubes and headers. The first ones usually have 25 to $44 \mathrm{~mm}$ outside diameter, while the second ones 100 to $350 \mathrm{~mm}$ respectively [3]. There are two different types of super-heaters dependent on the mode of heat transfer. Convection and radiant superheaters, where heat transfer is almost dependent on the parameters of the gas flow in the first case and highly dependent on the flue gas temperature in consequence of combustion in the second one. Dimensions are related to the operating pressure and total capacity.
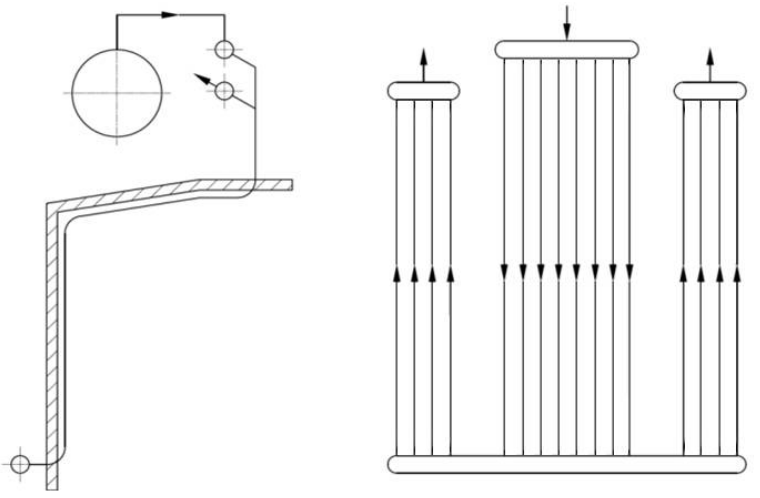

Fig. 1. Roof mounted design of super-heater.
Typical small power boilers, working under pressure from 10-12 $\mathrm{MPa}$, where preheating and evaporation are most important in the heat absorption process, the surface of super-heater is respectively smaller [2]. Located on the roof, small, radiant furnace super-heater can be used (Fig.1)[3]. Higher operating pressure requires greater super-heaters, which are divided in stages (Fig.2), where steam is mixed in headers to avoid uneven temperature distribution (Fig. 3). Also, quench coolers can be used as a temperature regulator. As materials of super-heater work under high pressure and temperature, allowable stress and economic factors are most crucial during the engineering process. Moreover, wall temperature calculations should be prepared, so that the most appropriate material should be used. Under 420 ${ }^{\circ} \mathrm{C}$ carbon steel can be applied. Above it, till $540{ }^{\circ} \mathrm{C}$, low-alloy ferritic steels should be used. From $500{ }^{\circ} \mathrm{C}$ till $600{ }^{\circ} \mathrm{C}$ ferritic-martensitic steel alloy is considered.

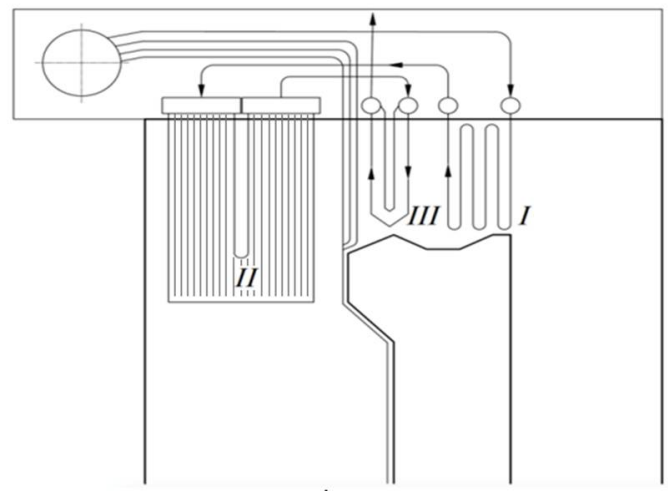

Fig. 2. Three-stage design of super-heater.

\footnotetext{
*Corresponding author: grandamariusz@gmail.com
} 
Furthermore, austenitic stainless steel can work even up to $650{ }^{\circ} \mathrm{C}$ but this kind of material is very expensive and difficult to weld as well [4].

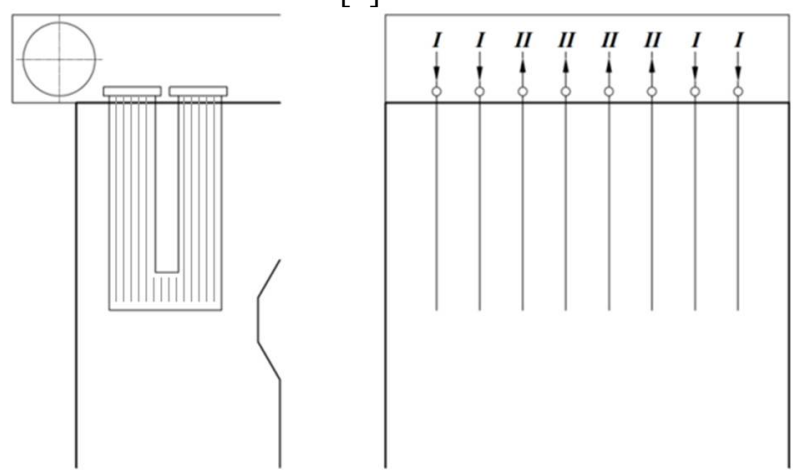

Fig. 3. Design of platen super-heater divided in stages.

\section{Turbulence}

\subsection{General information}

The flows occurring in nature can be divided into laminar, transitory and turbulent. The main and the most important criterion which describes every kind of flow is a dimensionless parameter called the Reynolds number $(R e)$, that can be expressed by the relation of inertia forces to viscous forces:

$$
R e=\rho U L / \mu,
$$

where $\rho$ is density, $U$ is the mean speed of the flow, $L$ is a characteristic dimension which is an internal diameter in case of cylindrical pipes and $\mu$ stands for dynamic viscosity respectively. Laminar flows, also called stratified are characterized by the fact that subsequent layers of the fluid slide on each other. The movement of the fluid elements is stable, and streamlines of the flow do not intersect. Unfortunately, most of the flows observed in nature are turbulent, where $R e \geq 2300$. A feature of such a flow is a chaotic movement of the fluid elements in a perpendicular direction to the general direction of the fluid motion, where the exchange of the fluid elements occurs between particular streamlines, and thus is characterized by the exchange of mass, momentum and energy. According to the Reynolds hypothesis, all parameters characterizing turbulent flow, such as speed, pressure and temperature, change over time around their time-averaged values [5, 6, 7]. Any flow value $f(x, y, z, t)$ can be expressed by the sum of the mean value $\bar{f}(x, y, z, t)$ and the fluctuation value $f^{\prime}(x, y, z, t)$, as below:

$$
f(x, y, z, t)=\bar{f}(x, y, z, t)+f^{\prime}(x, y, z, t)
$$

where the mean value is a time-averaged value:

$$
\bar{f}(x, y, z, t)=\frac{1}{\Delta t} \int_{t}^{t+\Delta t} f(x, y, z, t) d t
$$

Moreover, it should be noted, that the time interval must be chosen properly where the time-averaged value cannot change significantly. Further re-averaging of the time-averaged function value can be expressed as below:

$$
\bar{f}^{\prime}(x, y, z, t)=\frac{1}{\Delta t} \int_{t}^{t+\Delta t} f^{\prime}(x, y, z, t) d t=0
$$

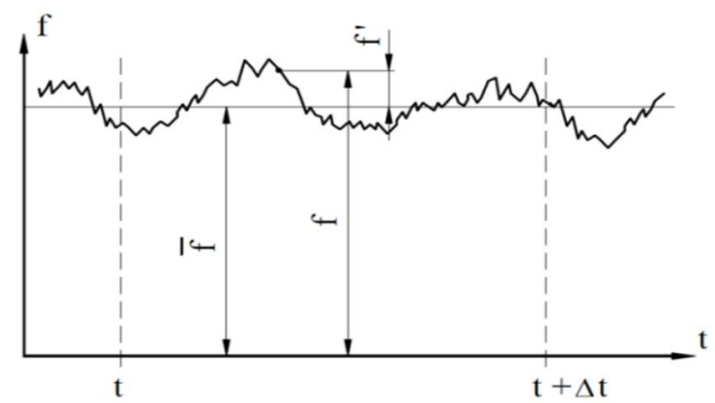

Fig. 4. Distribution of the flow value over time.

\subsection{Turbulence simulation}

\subsubsection{Direct Numerical Simulation}

Simulations of the turbulent flows can be carried out in terms of Direct Numerical Simulation method (DNS), which consists of direct solution of the Navier-Stokes equations, that enables accurate modelling of the phenomenon of turbulence. In this method, a mesh with elements smaller than individual swirls should be used. Also, the time step must be small enough to prevent crossing the mesh boundary by the analysed fluid element $[8,9]$. These requirements are related to the substantial amount of computing resources and the longtime of problem solving. It translates into the enormous cost of this type of analysis.

\subsubsection{Large Eddy Simulation}

Large Eddy Simulation (LES) method is based on the simulation of large-scale turbulent movements with determined kinetic energy, and modelling of smaller swirls where viscosity forces are considerable [10]. This method does not require such a large amount of computing resources and is very accurate in reflecting the actual turbulent flow, so that it is more and more willingly used as a tool in the CFD simulations [10].

\subsubsection{Reynolds Averaged Navier-Stokes Equations}

Most engineering simulations of turbulent flows are based on the Reynolds Averaged Navier-Stokes (RANS) equations where any instantaneous value can be decomposed as described before. This method is not as time consuming as the previous ones and can be used for practical purposes. The RANS equations are non-linear, where each component of fluctuation generates the unknown and an additional equation must be solved. In this particular situation turbulence models are provided, and the problem can be solved. Turbulence models can 
be divided into two groups in terms of the used hypothesis. The first group is based on the Bossinesq theory, where the Reynolds stress tensor is related to the strain-rate tensor expressed by the dynamic eddyviscosity [11, 12]. This group, which is referred to as the Eddy-Viscosity Models, contains single-equation, twoequation and multi-equation models. The most frequent used in industry are the two-equation models: $\mathrm{k}-\varepsilon, \mathrm{k}-\omega$, SST k- $\omega$.

The $\mathrm{k}-\varepsilon$ is the one of the most commercialized turbulence model, where turbulent kinetic energy $k$ and turbulent dissipation rate $\varepsilon$ are defined. The assumption of this model was its application to fully-developed turbulent flows with the high-Reynolds number [9, 11], so the k- $\varepsilon$ model should be avoided in modelling of the low-Reynolds number flows with a sophisticated path, where high-pressure gradients occur.

Another popular turbulence model in CFD simulations is proposed by D.C. Wilcox. That is the k- $\omega$ model, where turbulent kinetic energy $k$ and specific dissipation rate $\omega$ are employed. In this particular case, $\omega$ is the degree of turbulence dissipation related to the energy unit. On the basis of numerous investigations of flows along rough surfaces, obstacles with an adverse pressure gradient, this model is much more accurate in comparison to the others. However, with an increasing distance from the wall, a strong dependency on nondisturbed mean flow is observed, and the results of the simulation are not reliable [11].

The SST model is a hybrid of both $k-\varepsilon$ and $k-\omega$ models, which is a smooth transition from the first one, used for limited flows, whose purpose is the reflection of turbulence near the boundary layer, to the second one, which has its advantages in modelling of fully-developed flows. A number of challenging researches, investigations on aerospace profiles, flows with an adverse pressure gradient, and obstacle flows have shown much better results compared to other models [11].

\subsection{Velocity profile in turbulent flow}

The theory about the velocity profile in laminar pipe flow is well-developed, but when it comes to turbulent flow, the velocity profile expressions are still based on experimental data. The velocity profile of turbulent flow is also axisymmetric, nevertheless it is almost flat with a sharp drop close to the wall. Taking into consideration the velocity profile from the wall to the axis, four regions can be described [13]. At first, the very thin, near to the wall, viscous layer with nearly linear velocity distribution can be specified. Flow in this sub-layer is almost identical to laminar flow. Next is buffer layer where turbulent effects are important but not as important as viscous effects. After the buffer layer, overlap layer can be defined. Viscous effects are still dominant. Last, turbulent layer where viscous effects no longer matter, fills up the rest part of the flow. The variety of flow characteristics shows difficulties in an analytical description of the velocity profile. However, taking into account the viscous layer, it can be said that the shear stress is directly proportional to the viscosity of the fluid $[5,6,13]$ :

$$
\tau=\mu \frac{d u}{d y}
$$

where $\tau$ is the shear stress, $\mu$ is the dynamic viscosity, $u$ is the axial velocity and $y$ is the distance from the wall. Considering that velocity distribution, where speed takes values from zero on the wall to a certain value and velocity gradient is constant, the previous equation can be simplified, as given:

$$
\tau=\mu \frac{d u}{d y}=\mu \frac{u}{y}=\rho v \frac{u}{y} \Rightarrow \frac{\tau}{\rho}=\frac{v u}{y} .
$$

Introducing friction velocity as $\mathrm{u}_{*}=\sqrt{\tau / \rho}$, replacing it in the previous equation, velocity profile in viscous sublayer can be described by dimensionless parameters $\mathrm{u}^{+}$ and $\mathrm{y}^{+}$:

$$
\begin{gathered}
u_{*}^{2}=\frac{v u}{y} \\
u^{+}=\frac{u}{u_{*}} \text { and } y^{+}=\frac{y u_{*}}{v}
\end{gathered}
$$

The name of this equation is the law of the wall [13], and linear velocity profile for the smooth wall, where the influence of the turbulent effect is insignificant is valid for $\mathrm{y}^{+} \leq 5$ (Fig 3). According to the experimental data velocity profile for the turbulent layer was also described by power or logarithmic equations as given:

$$
\begin{gathered}
u^{+}=\frac{1}{\kappa} \ln \left(y^{+}\right)+B \\
\frac{u}{u_{\max }}=\left(\frac{y}{R}\right)^{1 / n} \text { or } \frac{u}{u_{\max }}=\left(1-\frac{r}{R}\right)^{1 / n} \\
\frac{\bar{u}}{u_{\max }}=\frac{2 n^{2}}{(n+1)(2 n+1)}
\end{gathered}
$$

where $\kappa, \mathrm{B}$ or $\mathrm{n}$ are experimental defined constants. Also $\mathrm{n}$, is Reynolds dependent constant:

$$
n=n(R e) \approx \frac{1}{\sqrt{\lambda}}
$$

where $\lambda$ is the Darcy friction factor. Both, power and logarithmic distribution are appropriate for the turbulent layer at range of $30<y^{+}<350$, while the buffer layer cannot be described by mathematic equations.

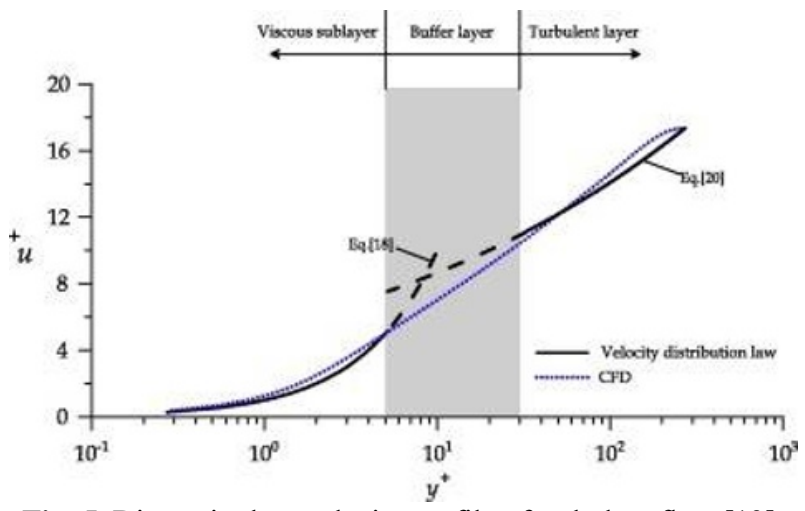

Fig. 5. Dimensionless velocity profile of turbulent flow [13]. 


\section{CFD simulations}

The subject of the analysis is the part of super-heater, that belongs to the furnace with a total capacity of 210 tons of steam per hour. The super-heater consists of 148 , $38 \times 4 \mathrm{~mm}$ 15HM steel pipes where a saturated steam flows under pressure of $10.5 \mathrm{MPa}$. The inlet temperature is $400{ }^{\circ} \mathrm{C}$, and heat flux is set at $50000 \mathrm{~W} / \mathrm{m}^{\wedge} 2$. The analysis is performed in Ansys CFX Academic environment to supply inner wall temperature and wall heat transfer coefficient through the pipe. The influence of the Earth's gravity is neglected.

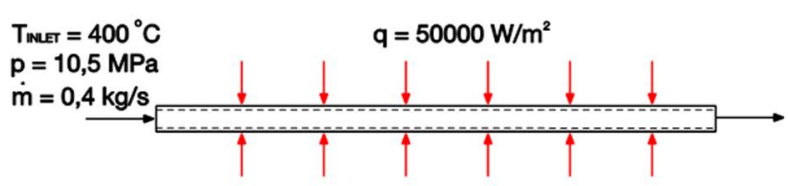

Fig. 6. Analysed problem.

In addition, due to consideration of fully developed flow, the length of 200 internal diameters is taken into account $[7,13]$. To simplify the problem, the quad pipe model is created and consequently symmetry boundary condition is applied. Two different meshes are generated (Table 1, Fig. 7, Fig. 8). Properties of 15HM steel were provided and entered in the CFD-tool (Table 2) [14].

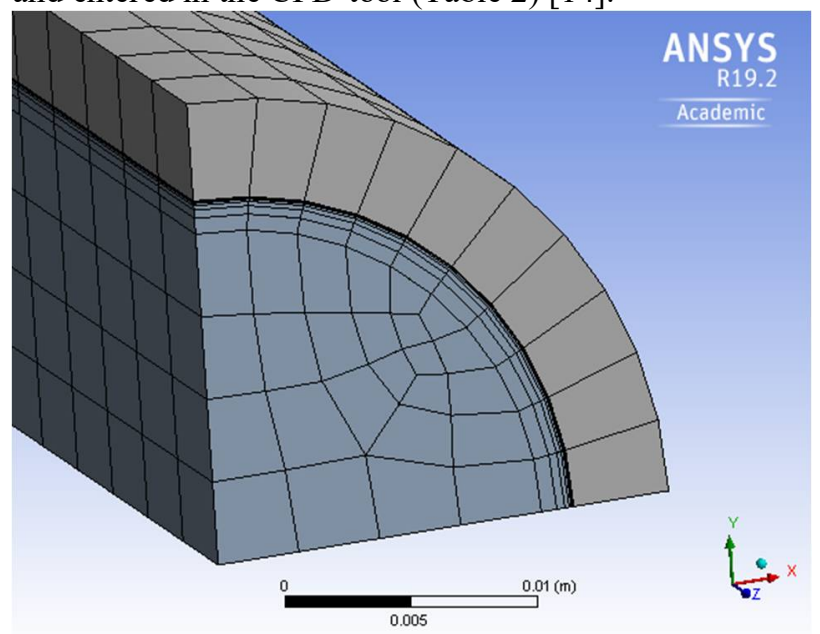

Fig. 7. Discrete model "Lite"

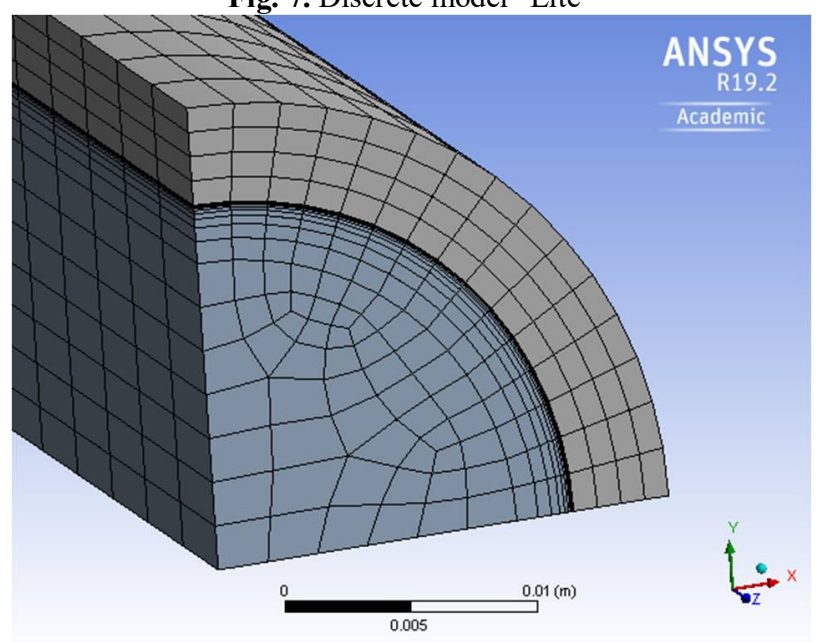

Fig. 8. Discrete model "Fine"
Table 1. Parameters of defined discrete models.

\begin{tabular}{lcc}
\hline Discrete model & "Lite" & "Fine" \\
\hline Number of Nodes & $296 \mathrm{k}$ & $576 \mathrm{k}$ \\
\hline Number of Elements & $256 \mathrm{k}$ & $514 \mathrm{k}$ \\
\hline Number of Inflation Layers & 10 & 14 \\
\hline
\end{tabular}

Table 2. Properties of $15 \mathrm{HM}$ steel.

\begin{tabular}{|c|c|c|c|c|}
\hline \multicolumn{2}{|c|}{$\begin{array}{c}\text { Steel } \\
15 \mathrm{HM} \\
13 \mathrm{CrMo} 44\end{array}$} & $\rho\left[\mathrm{kg} / \mathrm{m}^{3}\right]$ & $\begin{array}{l}k[W \\
/(m K)]\end{array}$ & $c_{p}[J /(k g K)]$ \\
\hline \multirow{7}{*}{ 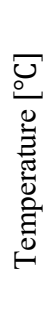 } & 20 & 7849 & 44,1 & 464 \\
\hline & 100 & 7825 & 44,6 & 480 \\
\hline & 200 & 7793 & 44,0 & 511 \\
\hline & 300 & 7759 & 42,2 & 555 \\
\hline & 400 & 7724 & 39,8 & 612 \\
\hline & 500 & 7687 & 37,0 & 681 \\
\hline & 600 & 7648 & 34,1 & 762 \\
\hline
\end{tabular}

The CFD simulation is carried out on both discrete and turbulence (k-epsilon, SST) until the convergence criteria are met (10e-12).

\section{Results}

Determining the phenomenon of convection in the CFD analysis is much more complicated than it is assumed, as CFD-tools often accept inappropriate reference temperature during convection analysis. In order to examine the value of the wall heat transfer coefficient determined by the CFD-Post, the definition of the wall heat transfer coefficient (WHTC) according to the third type boundary condition should be referred to $[5,7,15]$ :

$$
W H T C=\frac{\dot{q}_{\text {in }}}{T_{\text {in }}-T_{b}}
$$

where $\dot{q}_{\text {in }}$ is a heat flux provided to the inner wall, $T_{\text {in }}$ is the temperature of the inner wall and most important value $T_{b}$ is the bulk temperature. The bulk temperature reflects the average temperature of moving fluid in a particular cross section. To obtain real WHTC values, measurements at eleven equal-spaced cross section of inner wall temperature and bulk temperatures were gathered. The bulk temperature should have been measured as in the given equation:

$$
T_{b}=\frac{\int_{A_{w}} u T d A}{\int_{A_{w}} u d A}=\frac{2 \pi \int_{0}^{r_{w}} u T r d r}{2 \pi \int_{0}^{r_{w}} u r d r}
$$

and specific expression in CFD-Post was formulated:

\section{lengthInt(Velocity $u *$ Temperature*Y)@radius / lengthInt(Velocity $\left.u^{*} Y\right) @$ radius}

All data was gathered and presented in line charts (Fig. 9-16) to make comparison and conclusions. 


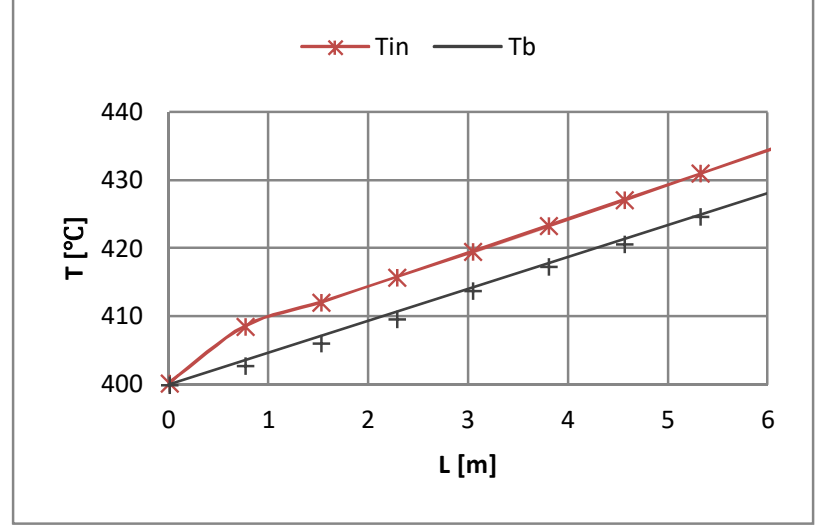

Fig. 9. Wall and bulk temperature in case of "Lite" and k-epsilon turbulence model.

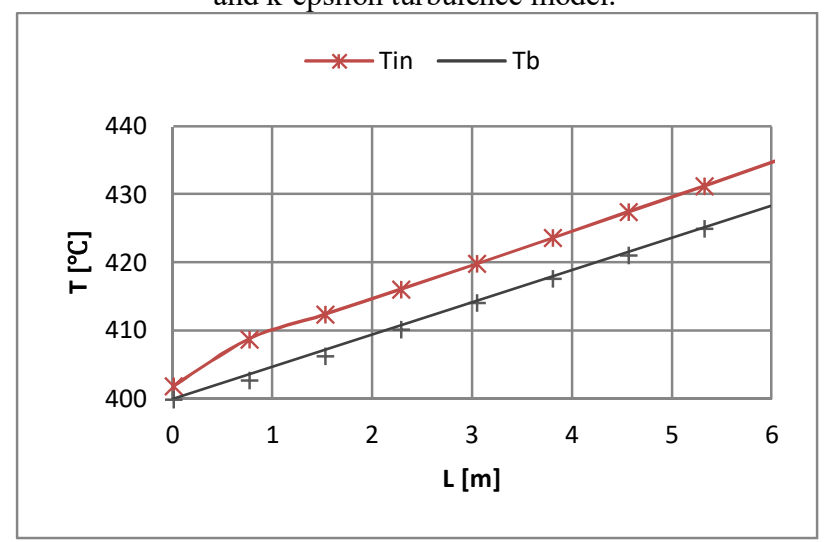

Fig. 11. Wall and bulk temperature in case of "Fine" and k-epsilon turbulence model.

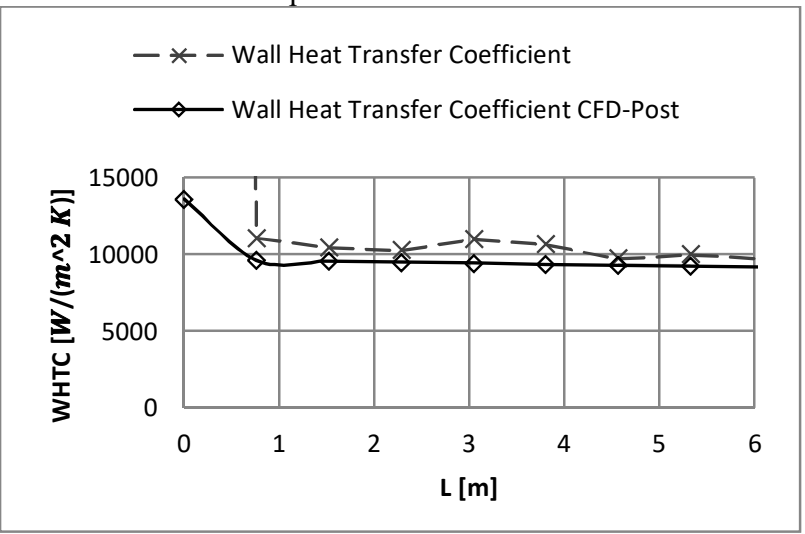

Fig. 13. WHTC comparison in case of "Lite" and k-epsilon turbulence model.

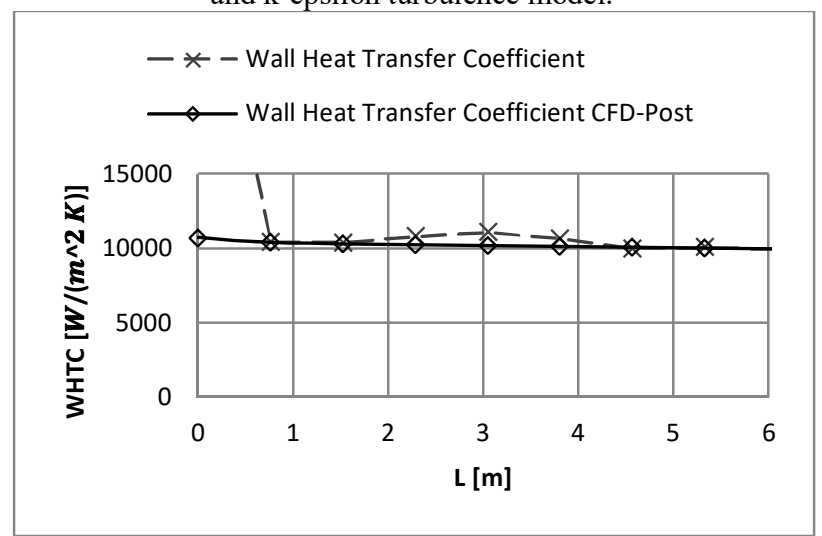

Fig. 15. WHTC comparison in case of "Fine" and k-epsilon turbulence model.

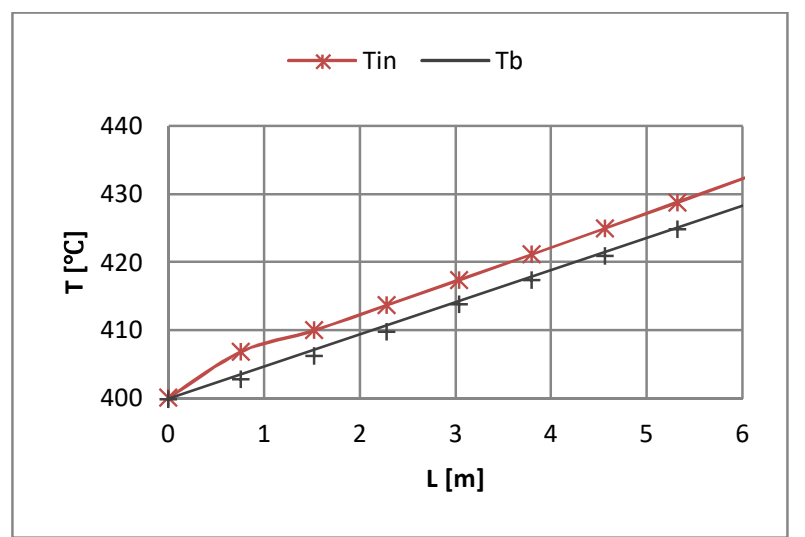

Fig. 10. Wall and bulk temperature in case of "Lite" and SST turbulence model.

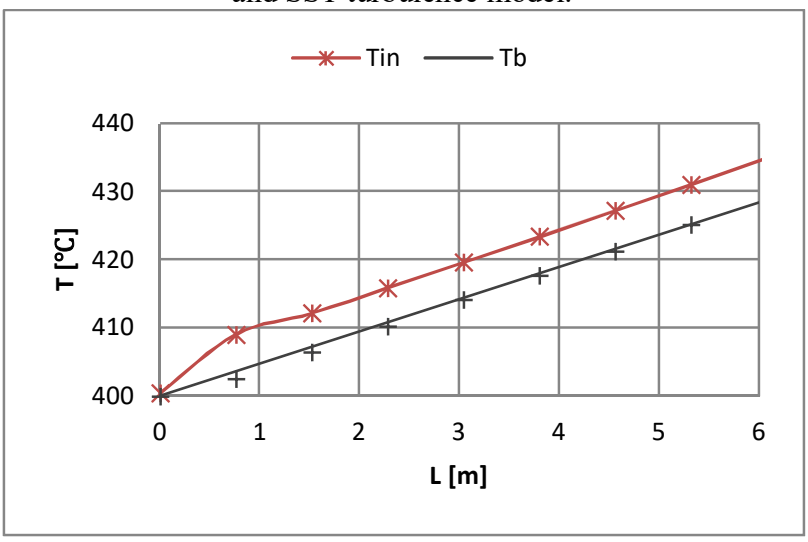

Fig. 12. Wall and bulk temperature in case of "Fine" and SST turbulence model.

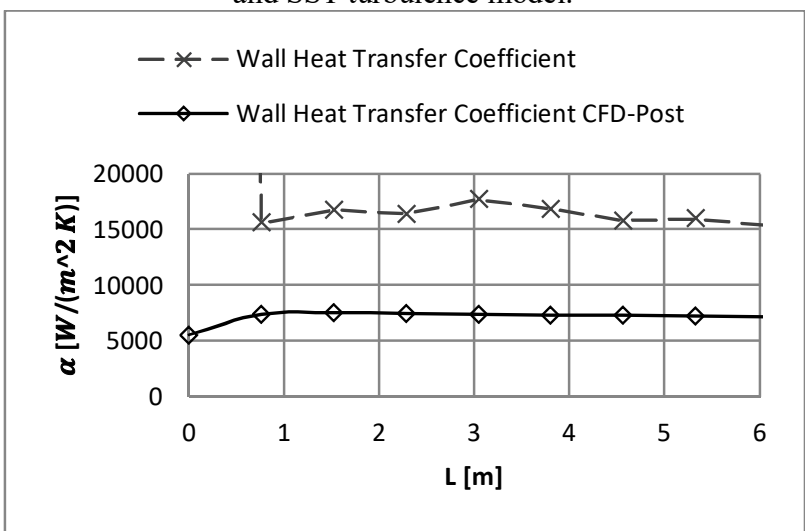

Fig. 14. WHTC comparison in case of "Lite" and SST turbulence model.

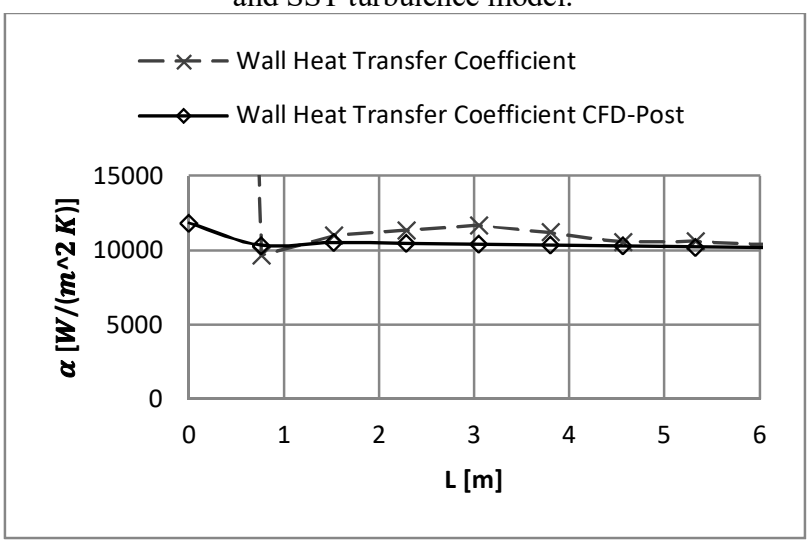

Fig. 16. WHTC comparison in case of "Fine" and SST turbulence model. 


\section{Discussion and conclusions}

The distribution of the inner wall and the appropriate bulk temperature are presented in Fig. 9-12. Differences between these temperatures in every section, in terms of Eq. (13), have an influence on the Wall Heat Transfer Coefficient. Distribution of both, the exact and obtained directly from CFD-tool Wall Heat Transfer Coefficients are compared in Fig. 13-16. Moreover, the comparison between the k-epsilon and the SST is shown on the left (Fig. 9, 11, 13, 15) and the right (Fig. 10, 12, 14, 16) column respectively. Hardly any differences between the discrete models in case of the k-epsilon turbulence model can be observed. There are no significant discrepancies in temperature distribution that translates to nearly identical results of the WHTC. According to the SST turbulence model, the density of the mesh is a significant factor as far as the accuracy is concerned. Even the WHTC obtained by the shortest way is far away from the other values. Furthermore, the distribution of each value is much more chaotic due to the applied turbulence model. The k-epsilon turbulence model is the most appropriate in case of the fully developed flow of steam under high pressure and temperature. Solutions are obtained with right accuracy and without huge computational effort. What is more, a slight difference between approaches to the WHTC is noticeable because CFD-tools consider wall adjacent temperature as a reference temperature.

Widespread CFD-tools are a quite reliable source of information, although experience as well as adequate knowledge in the CFD analysis are needed. Unfortunately, the Wall Heat Transfer Coefficient in the CFX-Pre is simplified in relation to its definition that is directly proportional to the heat flux and inversely proportional to the difference of the wall and the bulk temperatures. As we know, the wall temperature is uncomplicated to define even during the investigation, but the bulk temperature is a much more complex problem. Values received by CFD-tools consider wall adjacent temperature, which is the temperature of the first node next to the wall, so Wall Heat Transfer Coefficient is fully mesh dependent, so if density tends to infinity, the WHTC tends too. Therefore, during discretization, appropriate $\mathrm{y}+$ parameter should be taken into account. Moreover, there is no reason to use the SST turbulence model when the flow of steam under high pressure and temperature is under investigation. Based on the carried out analysis, it can be concluded that the value of the Wall Heat Transfer Coefficient is more or less $10,000 \mathrm{~W} /\left(\mathrm{m}^{2} \mathrm{~K}\right)$. Furthermore, the roughness of the pipe is also worth attention as it has a huge influence on convection. In this particular case, the pipe was smooth, that means roughness was neglected and additional investigation in terms of this parameter should be carried out.

\section{References}

[1] M. Pawlik, F. Strzelczyk, Elektrownie, Wydawnictwo WNT, 4, 43 (2014)

[2] J.B. Kitto, S.C, Stultz, Steam its generation and use, The Babcock \& Wilox Company, 41, 19.1-20, (2005)

[3] P. Orłowski, W. Dobrzański, E. Szwarc: Kotty parowe, Wydawnictwo WNT, 3, 285-302 (1979)

[4] P. Ludowski, D. Taler, J. Taler, Identification of thermal boundary conditions in heat exchangers of fluidized bed boilers, Applied Thermal Engineering, 58, 194-204, (2013)

[5] D. Taler, Obliczenia i badania eksperymentalne wymienników ciepła I, Wydawnictwo PK, (2016)

[6] K. Jeżowiecka-Kabsch, H. Szewczyk, Mechanika plynów, Oficyna wydawnicza Politechniki Wrocławskiej, 217-220 (2001)

[7] Y. A. Çengel, J.M. Cimbala, R.H. Turner, Fundamentals of thermo-fluid science, McGraw-Hill Higher Education, 869-891 (2012)

[8] Y. Kaneda, T. Ishihara, High-resolution direct numerical simulation of turbulence, Journal of Turbulence 7, (2006)

[9] M. Paszko, K. Łygas, , Wspótczesne metody modelowania przeplywów turbulentnych $w$ otoczeniu poruszajacego się autobusu miejskiego, Autobusy 12, 1270 (2016)

[10] Y. Zhiyin, Large-eddy simulation: Past, present and the future, Chinese Journal of Aeronautics 28, 11-24 (2014)

[11] M. Woelke, Eddy Viscosity Turbulence Models employed by Computional Fluid Dynamic, Wydawnictwa Naukowe Instytutu Lotnictwa, 92-109 (2007)

[12] P. Jamińska, Wpływ sposobu zdefiniowania struktury wiatru $w$ modelu turbulencji $k-\varepsilon w$ wersji standard na rozkład współczynnika ciśnienia na powierzchni ścian prostopadłościanu, Budownictwo i Architektura 10, 93-97 (2012)

[13] N.M.C. Martins, N.J.G Carriço, H.M. Ramos, D.I.C. Covas, Velocity-distribution in pressurized pipe flow using CFD: Accuracy and mesh analysis, Computers \& Fluids 105, 218-230 (2014)

[14] J. Taler, P. Duda: Rozwiazywanie prostych $i$ odwrotnych zagadnień przewodzenia ciepła, (2003)

[15] A. Neale, D. Derome, B. Blocken, J.E. Carmeliet, CFD calculation of connective heat transfer coefficients and validation- Part I: Laminar flow, (2006)

[16] CFX-Pre User's Guide, (2016) 